MAARTEN C. W. JANSSEN

Erasmus University Rotterdam

Rotterdam, The Netherlands

\title{
The Alleged Necessity of Microfoundations*
}

It is often said that models in the microfoundations literature derive macroeconomic results from the theory of individual behavior only. This paper examines two of the assumptions that are usually made in these models: market clearing and rational expectations. In the context of simple models it is shown that only in some special cases these assumptions can be derived from the fundamental notion that individuals behave rationally. Thus, the usual rationale for the microfoundations literature is challenged. The paper concludes with a more modest rationale for the "necessity" of microfoundations.

\section{Introduction}

Macroeconomics is in need of a microeconomic foundation. Nowadays, this is a widely accepted doctrine in the economics profession. Most economists take the necessity for a microeconomic foundation for granted. If arguments in favor of the necessity for microfoundations are cited, they often are of the following reductionist form. Society consists of individuals who are the only subjects that make economic decisions. So, in order to explain what is going on in the economy as a whole-for example, unemployment, inflation, business cycles-we have to understand the individual decisions from which a particular situation originates. I think that this "reductionist credo" itself is largely correct. However, if it is used as an argument in favor of the necessity for microeconomic foundations it is presupposed either that microeconomics is only concerned with individual behavior or that all microeconomic propositions can be derived from statements concerning individual decision

\footnotetext{
*This paper was written while I was visiting Duke University. The Netherlands Organization for Scientific Research is gratefully acknowledged for financial support. Earlier versions of this paper have been presented at seminars at the University of Groningen, Duke University, and the Erasmus University Rotterdam. I thank Willem Buiter, Harry Garretsen, Kevin Hoover, Neil de Marchi, two anonymous referees, and participants to the seminars for critical comments. Of course, I alone am responsible for the content of the paper.
} 
making. In this paper I will claim that both presuppositions are not correct: current microeconomics is, in my opinion, in need of an individualistic foundation. Because the microfoundations literature employs microeconomic models that lack individualistic foundations, a rationale for the microfoundations project cannot be derived from the above reductionist credo.

Some economists are inclined to regard the distinction between microeconomics and macroeconomics as a distinction between theories of individual behavior and theories concerning the economy as a whole. To these economists the above claim may seem to be paradoxical because for them microeconomics is by definition a theory of individual behavior. However, there are others who argue that this is not an appropriate demarcation criterion (see, for example, Machlup 1963 and Weintraub 1979). The term microfoundations is widely employed by new classical as well as new Keynesian economists for general equilibrium models that employ market clearing and rational expectations. In particular, new classical economists regard the adoption of market clearing and rational expectations as the only theoretically sound method to explain economic time series or, even more boldly, the only way to do economics properly (see Lucas 1981, 215-17). In order to make sense of this way of employing the term microfoundations we have to view general equilibrium theory as a part of microeconomics. General equilibrium theory is, however, frequently applied to economy-wide phenomena as well so that, according to the above demarcation criterion, it is also a part of macroeconomics. In my opinion this shows a fundamental weakness of the usefulness of this type of criterion to demarcate microeconomics from macroeconomics.

Another way to distinguish microeconomics and macroeconomics is to distinguish between a theory of the allocation of a given quantity of resources (microeconomics) and a theory of output and employment determination (macroeconomics). In what follows I will employ the terms microeconomics and macroeconomics in this way. When discussing individual behavior I simply use the phrase "theories of individual behavior." As a historical note it is interesting that traditionally the discipline was divided into the Theory of Value and Distribution on the one hand and the Theory of Money on the other hand. The distinction between microeconomics and macroeconomics became popular only after Keynes' General Theory (see Varian 1987). Keynes (1936, 292-93) made the following observation. 
The division of Economics between the Theory of Value and Distribution on the one hand and the Theory of Money on the other hand is, I think, a false division. The right dichotomy is, I suggest, between the Theory of the Individual Industry or Firm and of the rewards and the distribution of a given quantity of resources on the one hand and the Theory of Output and Employment as a whole on the other hand.

The concepts of microeconomics and macroeconomics became associated with Keynes's distinction between the Theory of the Individual Firm and the Theory of Aggregate Output and Employment, respectively. The General Theory certainly shaped the field of macroeconomics, and a change with respect to content associated the change in terminology in this field. This cannot be said of microeconomics. Microeconomics is still concerned with Theories of Value and Distribution and not only with theories of individual households or firms.

If it is granted that the rationale for the necessity of microfoundations (given in the beginning of the paper) fails, one may wonder whether other rationales exist. Some authors (for example, Hahn 1983, 223) pose that there cannot be two separate subjects (microeconomics and macroeconomics) within one discipline. In other words, there can only be one economic theory and the rationale for providing macroeconomics with microfoundations is to unify the two subjects. General equilibrium theorists, of course, believe that their theory should be used as the basis of this unification. Although unification is a legitimate goal to achieve scientific progress, it will be clear that providing macroeconomics with a microeconomic foundation is a necessity only from a general equilibrium point of view (compare Shubik 1975).

The rest of the paper elaborates upon the above observations and illustrates the arguments in the context of simple models. In Sections 2 and 3 the observation that microeconomics is in need of an individualistic foundation will be supported by demonstrating that the hypotheses of rational expectations and market clearing are in need of individualistic foundations. In the remainder of the paper I will show that the microfoundations project can be regarded as a general equilibrium research methodology in which the difficulties of providing the market clearing assumption and the rational expectations hypothesis with individualistic foundations are left undiscussed. 


\section{2. "Rational" Expectations}

It is well known that a variety of rational expectations hypotheses exists (see Frydman and Phelps 1983). The most frequently employed hypothesis is of the following form.

REH The subjective expectation of all individuals equals the objective mathematical expectation of the relevant theory conditioned on the data available when the expectation was formed.

In this section I will show that there are a number of cases in which there is no theory of rational behavior on the part of individual agents from which this form of the rational expectations hypothesis can be derived. Most critical discussions either challenge the descriptive adequacy of the REH or they doubt whether agents are able to learn the "true" (parameters of the) model (see Frydman 1982). Instead, I will criticize the internal consistency of the REH. Specifically, I will assume that agents know the true model, and I will discuss whether the REH is a logical consequence of rational individual behavior in models where at least two rational agents are distinguished. In this respect the analysis below differs from Haltiwanger and Waldman (1989) because their paper shows that it is not rational to have expectations that conform to the REH if some agents have adaptive expectations, that is, they behave irrationally.

First, I discuss a case in which both the government and the public act as rational agents. It is shown that there are two relevant theories of rational behavior which prescribe two different actions. This first case abstracts from the fact that the public is not one rational agent. The second case distinguishes multiple rational agents within the public, but abstracts from the fact that the government is a decision maker. This second case shows that correct expectations may depend on expectations of other agents' expectations. The third subsection looks at whether restrictions on higher order levels of expectations can be justified in terms of (common knowledge of) the rationality of individual agents.

\section{The Government and the Public as Two Rational Agents}

In an interesting article Frydman, O'Driscoll, and Schotter (1982) apply the so-called Newcomb's paradox to a case in which a monetary authority must make a decision in a situation in which its payoff is affected by whether or not its action is predicted by the public. They show that if the public has good predictive powers, a unique rational decision of the monetary authority may not exist. 
To illustrate the argument I use the following simple, but widely used, new classical model, which was originally proposed by Lucas (1973). This model will be used to illustrate subsequent arguments as well. All variables refer to the same period $t$ and are measured in logs.

$$
\begin{aligned}
& Y^{s}=Y^{*}+\alpha\left(P-P^{e}\right) \quad \alpha>0, \\
& Y^{d}=M-P+V, \\
& Y^{s}=Y^{d}
\end{aligned}
$$

where $Y^{s}, Y^{d}$ are aggregate supply and demand; $Y^{*}$ is full-employment output; $P$ is the price level; $P^{e}$ is the price level expected by the public; $M$ is the money stock, and $V$ is a constant velocity of money circulation.

Solving this system of equations yields

$$
P=(1 / 1+\alpha)(M+V)+(\alpha / 1+\alpha) P^{e}-(1 / 1+\alpha) Y^{*} .
$$

It is assumed that the public knows the value of $\alpha$. Rational price expectations in the sense of REH can be calculated in the usual way by taking expectations of both sides of this equation and solving for $P^{e}$ :

$$
\begin{aligned}
P^{e} & =M^{e}+V-Y^{*}, \\
P & =\left(M+\alpha M^{e}\right) /(1+\alpha)+\left(V-Y^{*}\right),
\end{aligned}
$$

where $M^{e}$, the level of the money stock expected by the public, is crucial for the formation of a price expectation. Using Equations (4) and (5) we arrive at the following solution:

$$
Y-Y^{*}=\alpha\left(M-M^{e}\right) /(1+\alpha) .
$$

This is the well-known result that, in Lucas's monetary model of the business cycle, only an unexpected monetary policy has an effect on aggregate output. In order to facilitate the argument, suppose that the monetary authority has only two policy options available. It can either choose a low level of money supply $\left(M_{L}\right)$ or a high level of money supply $\left(M_{H}\right)$. If the public correctly anticipates the monetary policy, then $P=P^{e}$ and $Y=Y^{*}$. Equations (5) and 
(6) then reveal that, in the case of a low money supply, $P^{e}$ and $P$ are lower than in the case of a high money supply. If a low money supply is expected, while the monetary authority chooses a high money supply, $P>P^{e}$ and $Y>Y^{*}$. The reverse inequalities hold true if a high money supply is expected, while the monetary authority chooses a low level of the money supply.

It is assumed that the monetary authority has a preference ordering over the four possible outcomes. This is described by the following matrix.

\begin{tabular}{cccc} 
& & \multicolumn{2}{c}{ Public } \\
& & Expect $M_{L}$ & $\operatorname{Expect} M_{H}$ \\
$\begin{array}{l}\text { Monetary } \\
\text { Authority }\end{array}$ & & & \\
& & & $U\left(M_{L}, M_{H}\right)$ \\
& Choose $M_{H}$ & $U\left(M_{H}, M_{L}\right)$ & $U\left(M_{H}, M_{H}\right)$
\end{tabular}

In this matrix $U\left(M_{H}, M_{L}\right)$, for example, is the von Neumann-Morgenstern utility of the monetary authority related to the situation in which the public expects $M_{L}$ and the authority chooses $M_{H}$. Following Frydman, O'Driscoll, and Schotter (1982) I assume that $U\left(M_{H}\right.$, $\left.M_{L}\right)>U\left(M_{L}, M_{L}\right)>U\left(M_{H}, M_{H}\right)>U\left(M_{L}, M_{H}\right)$.

Let $\omega$ denote the (subjective) probability that the public correctly anticipates the monetary policy. The monetary authority's expected utility of choosing $M_{L}$ and $M_{H}$ can then be written as $\omega U\left(M_{L}\right.$, $\left.M_{L}\right)+(1-\omega) U\left(M_{L}, M_{H}\right)$ and $(1-\omega) U\left(M_{H}, M_{L}\right)+\omega U\left(M_{H}, M_{H}\right)$, respectively. If the public is a good predictor of the monetary policy, that is, if $\omega$ is close to 1 , then $M_{L}$ maximizes the authority's expected utility. ${ }^{2}$ However, as $U\left(M_{H}, M_{L}\right)>U\left(M_{L}, M_{L}\right)$ and $U\left(M_{H}\right.$, $\left.M_{H}\right)>U\left(M_{L}, M_{H}\right), M_{H}$ dominates $M_{L}$.

There has been much debate on Newcomb's paradox (see O'Flaherty 1985 for an overview). Rational expectations in the sense of REH clearly means that $\omega$ is close to or equal to 1 . In this case the authority's decision situation can be approached from two relevant theories concerning rational behavior. In the Bayesian view of rationality (see Tan and Werlang 1988) agents should maximize their (subjective) expected utility. This leads to the choice of $M_{L}$. The other view is that agents should not choose a dominated strat-

\footnotetext{
${ }^{1} M_{L}$ maximizes the authority's expected utility if $\omega$ is such that $\omega /(1-\omega)$ $>\left[U\left(M_{H}, M_{L}\right)-U\left(M_{L}, M_{H}\right)\right] /\left[U\left(M_{L}, M_{L}\right)-U\left(M_{H}, M_{H}\right)\right]$.
} 
egy. The application of this Dominance Principle leads to the choice of $M_{H}$. So, on the basis of considerations of rationality only it is neither clear what the monetary authority should do nor what the public should expect the authority to do. Of course, in specific cases the authority may use extra-rational processes (for example, rules of thumb) which prescribe a unique action. The public may know this and may use the knowledge to form their expectations. However, these expectations do not follow from the description of the theory. The REH does not make much sense in these cases because relevant theories of rational behavior contradict each other, and processes which prescribe a definite choice are extra-rational. This conclusion holds in quite a number of models in which both the government and the public are regarded as rational agents.

\section{Rational Expectations as Nash Equilibrium}

Above we have concentrated on the interaction between the expectations of the monetary authority and the public. The public was regarded as one homogeneous group and the expectations of the public were represented by the expectations of one representative decision maker. However, the assumption of price-taking behavior implies that each supplier is negligibly small relative to the size of the economy. It is thus necessary to assume that a large number, say $n$, of suppliers exists who may have different expectations. In this subsection I concentrate on the interaction between expectations of different suppliers. In order to do so I rewrite Equation (1) as

$$
Y^{s}=Y^{*}+\alpha / n \sum_{i=1}^{n}\left\{P-P^{e}(i)\right\} ; \quad \alpha>0,
$$

where $P^{e}(i)$ is the price expectation held by supplier $i$. The price expectation for agent $i$ that turns out to be correct ex post, $p^{c e}(i)$, is then equal to

$$
\begin{aligned}
P^{c e}(i)=P . & =\frac{n}{n+\alpha n-\alpha}\left(M+V-Y^{*}\right) \\
& =\frac{\alpha}{n+\alpha n-\alpha} \sum_{j \neq i}^{n} P^{e}(j) .
\end{aligned}
$$

However, if all suppliers have to form expectations at the same moment in time they are not informed about the other suppliers' ex- 
pectations. I will define an individual rational price expectation for agent $i, P^{r e}(i)$, as the best expectation agent $i$ is able to form given the information available to him. Using Equations ( $\left.1^{\prime}\right),(2)$, and (3) we arrive at

$$
P^{r e}(i)=\frac{n}{n+\alpha n-\alpha}\left(M+V-Y^{*}\right)+\frac{\alpha}{n+\alpha n-\alpha} \sum_{j \neq i}^{n} P^{e}(j(i)),
$$

where $P^{e}(j(i))$ is the expectation agent $j \neq i$ is assumed to hold by agent $i$.

The question we are interested in is whether $\mathrm{REH}$ is a logical consequence of the basic hypothesis that agents have individual rational price expectations. Comparing Equations (5) and (9) immediately shows that this is not always the case. One may wonder under what condition individual rational price expectations do coincide with $\mathrm{REH}$, that is, when does

$$
P^{r e}(i)=M+V-Y^{*}
$$

hold true for all $i$. Simple algebra shows that this is the case if, and only if,

$$
\frac{1}{n-1} \sum_{j \neq i} P^{e}(j(i))=M+V-Y^{*}
$$

This means that all individuals have to expect that the average price expectation of all other agents equals the REH price expectation. An important special case occurs when all agents expect the REH price to prevail and this is expected by all agents. In this case there is a Nash equilibrium in expectations. Accordingly, the REH can be regarded as an equilibrium assumption (see also Evans 1983). Recent game theoretic literature reveals, however, that in general the Nash equilibrium concept is not a simple consequence of rational behavior on the part of individuals. On the contrary, some coordinating device has to assure that individuals play Nash equilibrium strategies (see Tan and Werlang 1988 and Gul 1989).

This result indicates that in a multi-individual economy individual rationality and knowledge of the true model are not sufficient to justify REH. All individuals have to expect that the average expectation is in conformity with the REH. In other words, in order to justify the $\mathrm{REH}$ we have to make a stringent assumption about 
expectations of expectations. ${ }^{2}$ If the economy is supposed to consist of one individual, as is the case in many new classical models, these difficulties do not arise because the individual agent is then in a position to derive a unique relation between his individual expectations and "aggregate" outcomes. In a multi-individual economy this is not possible because aggregate outcomes are also determined by other agents' expectations.

\section{Rational Expectations and Common Knowledge of Rationality}

In the previous subsection we have seen that individual rational price expectations coincide with the REH price expectation only if all individual agents expect the average price expectation to conform to the REH. In some cases this stringent assumption on second-order expectations can be derived from the more fundamental notion that individual agents are rational and that this rationality is common knowledge. ${ }^{3}$ This will be illustrated by means of the following simple partial equilibrium model. After this illustration I come back to the new classical model. Aggregate supply in period $t, q_{t}^{s}$, depends on the sum of the expected price $p_{t}^{e}(j)$. Demand, $q_{t}^{d}$, depends on the realized price, $p_{t}$. The model is assumed to be common knowledge.

$$
\begin{array}{ll}
q_{t}^{d}=\alpha_{1}-\beta_{1} p_{t}, & \text { if } p_{t} \leq \alpha_{1} / \beta_{1} ; \alpha_{1}, \beta_{1}>0 ; \\
q_{t}^{d}=0, & \text { if } p_{t}>\alpha_{1} / \beta_{1} ; \\
q_{t}^{s}=\alpha_{2}+\beta_{2} / n \sum_{j=1}^{n} p_{t}^{e}(j) \quad \alpha_{2}<\alpha_{1} ; \beta_{2}>0 ; \\
q_{t}^{s}=q_{t}^{d} .
\end{array}
$$

It is easy to see that the rational price expectation in the sense of REH equals $p_{t}^{e}=\left(\alpha_{1}-\alpha_{2}\right) /\left(\beta_{1}+\beta_{2}\right)$. Any other expected price

${ }^{2}$ It is interesting to remark that Keynes (1936) writes about higher order expectations when discussing the famous beauty contest; see also Frydman (1982).

${ }^{3} \mathrm{~A}$ fact is common knowledge if not only everybody knows that it is true, but also that everybody knows that everybody knows it is true and so on. Bernheim (1984) and Pearce (1984) argue that common knowledge of individual rationality is logically equivalent to the concept of "rationalizability." In the arguments that follow I employ the concept of iterative elimination of dominated strategies, which is very close to rationalizability (see Tan and Werlang 1988). 
will not be realized. In general, the relation between prices and expected prices is the following:

$$
p_{t}=\left(\alpha_{1}-\alpha_{2}\right) / \beta_{1}-\beta_{2} / n \beta_{1} \sum_{j=1}^{n} p_{t}^{e}(j) .
$$

The argument runs as follows. Prices, hence the expected price, cannot fall below 0 . Thus, all agents know that aggregate supply will be greater than $\alpha_{2}$ (see Equation [13]). This means that all suppliers know (on the basis of the demand curve) that price will never exceed $\left(\alpha_{1}-\alpha_{2}\right) / \beta_{1}$. This fact is common knowledge. Accordingly, a rational supplier will never expect a price larger than $\left(\alpha_{1}-\alpha_{2}\right)$ $/ \beta_{1}$, and he knows that the other suppliers will not expect a larger price as well. Using this knowledge and Equation (15), the suppliers know that (and they know that others know that, and so on).

$$
p_{t} \geq \frac{\alpha_{1}-\alpha_{2}}{\beta_{1}}-\frac{\beta_{2}}{\beta_{1}} \frac{\alpha_{1}-\alpha_{2}}{\beta_{1}} .
$$

Applying the same argument as above, all suppliers also know that

$$
p_{t} \leq \frac{\alpha_{1}-\alpha_{2}}{\beta_{1}}\left[1-\frac{\beta_{2}}{\beta_{1}}+\left(\frac{\beta_{2}}{\beta_{1}}\right)^{2}\right] \text {. }
$$

So, rational agents will not expect a price that does not satisfy this constraint. Eventually, that is, if the argument is applied an infinite number of times, all suppliers know that

$$
p_{t} \leq \frac{\alpha_{1}-\alpha_{2}}{\beta_{1}}\left[1-\frac{\beta_{2}}{\beta_{1}}+\left(\frac{\beta_{2}}{\beta_{1}}\right)^{2}-\left(\frac{\beta_{2}}{\beta_{1}}\right)^{3}+\ldots\right] .
$$

Provided that $\beta_{2}<\beta_{1}$, this expression equals $\left(\alpha_{1}-\alpha_{2}\right) /\left(\beta_{1}+\beta_{2}\right)$, which is the equilibrium price. By the same token all suppliers know that $p_{t} \geq\left(\alpha_{1}-\alpha_{2}\right) /\left(\beta_{1}+\beta_{2}\right)$. Thus, provided that $\beta_{2}<\beta_{1}$, the only individual rational price expectation that is consistent with common knowledge is the rational expectations price. ${ }^{4}$ Note that the argument by means of which this conclusion is reached is similar to the familiar argument of the Cobweb Theorem. The condition $\beta_{2}<\beta_{1}$ is the stability condition of the Cobweb process. The Cobweb process is a dynamic process in real time with "naive expectations,"

${ }^{4}$ For a more extended discussion of the above argument, see Guesnerie (1989). 
while the present argument concerns a dynamic process in notional time with "individual rational expectations."

Returning to our simple new classical model one may wonder whether similar arguments apply to this case. At first sight such an application may seem to be appropriate. The relation between realized prices and expected prices is

$$
P=\left\{M+V-Y^{*}+\alpha / n \sum_{j=1}^{n} P^{e}(j)\right\} /(1+\alpha) .
$$

However, in the context of the new classical model there are no "natural constraints" on prices (as say $P \geq 0$ ) that trigger off the elimination process. This is because the variables are measured in logs and logs can take on all real values. The reason for the model to be written in logs is that the demand equation is just a version of the Quantity Theory of Money. So, without changing the model there is no way to justify the assumption on second order expectations (or, equivalently, the Nash assumption) on the basis of common knowledge of individual rationality.

One way to trigger the elimination process is to allow for an independent authority, say the government, who announces credible price and/or quantity restrictions. Let us imagine that the government announces the quantity restriction that $Y \geq 0$. In this case all firms know that the largest price to be expected is equal to $M+V$. Applying the above argument gives that firms know that prices have to fulfill the following requirement:

$$
P \leq\left\{M+V-Y^{*}+\alpha(M+V)\right\} /(1+\alpha)=M+V-\frac{1}{1+\alpha} Y^{*} .
$$

A subsequent application of the above argument gives

$$
\begin{aligned}
P & \leq M+V-\frac{1}{1+\alpha}\left[1+\frac{\alpha}{1+\alpha}+\left(\frac{\alpha}{1+\alpha}\right)^{2}+\ldots\right] Y^{*} \\
& =M+V-Y^{*} .
\end{aligned}
$$

The restriction $Y \geq 0$, however, does not eliminate prices below $M+V-Y^{*}$. In order to eliminate these prices as well, another restriction has to be added. It is easy to check that, for example, $P \geq 0$ will do the job.

If the variables in the model are not measured in logs the 
supply equation can still be chosen to be of a linear form and the Quantity Equation is $m v=p y^{d}$, where lower case letters indicate variables not measured in logs. In this case there is a natural constraint that prices have to be nonnegative, and it can be shown that this implies $p^{e}(i) \geq(m v) / y^{*}$, which is the equilibrium price. There is, however, no natural upper limit on prices so that the government has a role to play in this case as well.

Of course, the introduction of a government in the above model is at odds with the new classical emphasis on the efficiency of laissez faire. However, without a central authority a decentralized process of expectations formation does not converge to expectations that are in conformity with the REH in this model.

\section{Market Clearing}

\section{A Non-Individualistic Explanation of Market Prices}

In the previous section we saw that the REH lacks a solid foundation in the theory of rational behavior once at least two rational agents are distinguished in a model. The logical difficulties I have pointed at do not occur in models with only one decision maker. Before analyzing whether there is a rationale in terms of individual behavior for the market clearing assumption, it is convenient to consider another fundamental difference between a Robinson Crusoe economy and an economy consisting of two or more individuals. Robinson Crusoe may produce and consume goods, he may save them for future consumption, and so on. These are also the activities individuals may undertake in an economy consisting of two or more individuals. However, in the latter type of economy individuals are also able to exchange goods in which case prices (or, better, exchange ratios) emerge. Exchange and exchange ratios have no meaning in a Robinson Crusoe economy. The interesting question from this perspective then is whether, in the context of general equilibrium theory, exchange and exchange ratios can be explained in terms of a decentralized process of individual decisions.

This may seem to be a rather artificial way to characterize some of the difficulties (new classical) economic theory faces. I think, however, that it is not. Among others, Kydland and Prescott (1982) and Long and Plosser (1983) construct a Robinson Crusoe model of the business cycle. Such a model may be able to explain the actual pattern of consumption and production, but it cannot explain the level of exchange and exchange ratios in an economy because, be- 
fore Friday arrives, there is no other person Robinson Crusoe can exchange goods with. Of course, an economist may explain Robinson Crusoe's behavior in terms of the theoretical concept of shadow prices. The only point I want to make here is that, in a Robinson Crusoe economy, there are no such observable things as prices which have to be explained.

Prices are typically phenomena that arise from the interaction between different individuals. The most influential way in which prices are "explained" in economics and the one new classical economists often adhere to is to assume that observed prices are market clearing prices. Prices are determined by the impersonal forces of the market, that is, prices have to be such that all excess demands equal zero. But, and this is essential, the way the theory of individual economic behavior is formalized within the general equilibrium method does not guarantee that prices bring about a situation in which excess demands equal zero; all individuals take prices as given. The general equilibrium method simply assumes the existence of markets that coordinate individual economic activity (see also Janssen 1989).

Of course, there are many economists who have expressed similar thoughts. Arrow (1959), in search of a rationale of the market clearing axiom, notes that this axiom is often regarded as the limit of a trial and error process known as the Law of Demand and Supply. He poses that this law is not on the same logical level as the hypotheses underlying the demand and supply schedules because

it is not explained whose decision it is to change prices. . . Each individual participant is supposed to take prices as given and determine his choices as to purchases and sales accordingly; there is no one left over whose job it is to make a decision on price. (Arrow 1959, 43)

In other words, from an individualistic point of view, the explanation of prices is left up in the air: a fictitious auctioneer and an Invisible Hand are non-individualistic, that is, centralized, devices.

\section{Individualistic Foundations for Market Clearing}

Returning to our new classical model, it is easy to see that the above observations challenge the individualistic foundations of Equation (3). If, however, individual agents are considered as price setters, then Equation (1) or (2) has to be adapted as well. In the 
rest of this section I will consider a similar question to the question posed in Section 2, namely, whether the market clearing condition can be derived from the more fundamental notion that individual agents are rational and that this rationality is common knowledge.

In order to do so, I consider firms as price setters. The form of the argument will first be illustrated by means of a simple model in which profit maximizing firms are assumed to produce a homogeneous product. There are $n$ such firms, and all firms have access to the same constant returns to scale production technology. Marginal costs are constant and represented by $\gamma$. Demand will be equally divided among the firms that charge the lowest price. Aggregate demand is assumed to take the form of Equation (12) in which $p$ has to be interpreted as the market price, that is, the lowest price charged by the firms. Furthermore, assume that firms can choose prices from a discrete price space only and let the distance between two adjacent prices be equal to $\rho$, where $\rho$ is a small positive number. ${ }^{5}$ The above model is assumed to be common knowledge.

The assumptions indicate that profits of individual firms are given by

$$
\pi_{i}\left(p_{i}, p_{-i}\right)= \begin{cases}0 & \text { if } p_{i}>\min p_{-i} \\ \frac{1}{n^{*}}\left(p_{i}-\gamma\right)\left(\alpha_{1}-\beta_{1} p_{i}\right) & \text { if } p_{i}=\min p_{-i} \\ \left(p_{i}-\gamma\right)\left[\alpha-\beta_{1} p_{i}\right] & \text { if } p_{i}<\min p_{-i}\end{cases}
$$

where $p_{-i}$ is the vector of prices set by all firms except firm $i$; min $p_{-i}$ is the minimum of the elements of this vector; $n^{*}$ is the number of firms that charge the lowest price; and $\pi_{i}$ is the profit made by firm $i$.

We look for an iterative process that converges to the result that firms set their price equal to the market clearing price, which is $\gamma$. In the previous section the starting point of the iterative process was the recognition that prices have to be nonnegative. In the present case we are able to define the starting points more narrowly. It is clear that firms will never set a price below $\gamma$. At the other extreme, firms will never set a price above the monopoly

${ }^{5}$ The argument given below relies upon a discrete price space. This is because if firms could pick a price out of a continuum the highest price that is left over after each elimination step is not well defined. 
price, which is $p^{m}=\left(\alpha_{1}+\beta_{1} \gamma\right) / 2 \beta_{1}{ }^{6}$ This can easily be seen by distinguishing the following three cases:

(a) if $\min p_{-i}<p^{m} \quad \pi_{i}\left(p_{i}, p_{-i}\right)=\pi_{i}\left(p^{m}, p_{-i}\right)=0 \quad$ for all $p_{i}>p^{m}$.

(b) if $\min p_{-i}=p^{m} \begin{cases}\pi_{i}\left(p_{i}, p_{-i}\right)=0 & \text { for all } p_{i}>p^{m} . \\ \pi_{i}\left(p^{m}, p_{-i}\right)=\frac{1}{n^{*}}\left(p_{i}-\alpha\right)\left[\alpha_{1}-\beta_{1} p_{i}^{m}\right]>0 . & \end{cases}$

(c) if $\min p_{-i}>p^{m} \quad 0 \leq \pi_{i}\left(p_{i}, p_{-i}\right)<\pi_{i}\left(p^{m}, p_{-i}\right) \quad$ for all $p_{i}>p^{m}$.

by the definition of $p^{m}$.

In each case $\pi_{i}\left(p_{i}, p_{-i}\right) \leq \pi_{i}\left(p^{m}, p_{-i}\right)$ for all $p_{i}>p^{m}$. Hence, profit maximizing firms never set a price that is larger than $p^{m}{ }^{7}$

So, firms only consider prices between $y$ and $p^{m}$. This fact is common knowledge. In each successive step of the iterated elimination process at least one price can be skipped. In order to see this let $\bar{p}$ be the largest price after an arbitrary number of elimination steps. Note that for all $\vec{p}$ such that $\gamma+\rho \leq \bar{p} \leq p^{m}$ the following holds:

(a) if $\min p_{-i}<\bar{p}-\rho$, then $\pi_{i}\left(\bar{p}-\rho, p_{-i}\right)=\pi_{i}\left(\bar{p}, p_{-i}\right)=0 \quad$ for all $p_{i}>\bar{p}$;

(b) if $\min p_{-i}=\bar{p}-\rho, \quad$ then $\pi_{i}\left(\bar{p}-\rho, p_{-i}\right)=\frac{1}{n^{*}}(\bar{p}-\rho-\gamma)$

$$
\begin{aligned}
& \cdot\left(\alpha_{1}-\beta_{1} \bar{p}+\alpha_{2} \rho\right) \\
& >\pi_{i}\left(\bar{p}, p_{-i}\right)=0
\end{aligned}
$$

(c) if $\min p_{-i}=\bar{p}$, then $\left\{\begin{array}{l}\pi_{i}\left(\bar{p}-\rho, p_{-i}\right)=(\bar{p}-\rho-\gamma)\left[\alpha_{1}-\beta_{1} \bar{p}+\alpha_{2} \rho\right] \\ \pi_{i}\left(\bar{p}, p_{-i}\right)=\frac{1}{n^{*}}(\bar{p}-\gamma)\left[\alpha_{1}-\beta_{1} \bar{p}\right]\end{array}\right.$

${ }^{6}$ In order to have an interesting model there has to be at least one price greater than $\gamma$ that yields a positive demand. This gives us the condition $\alpha_{1} / \beta_{1}>\gamma$ so that $\gamma<p^{m}<\alpha_{1} / \beta_{1}$.

${ }^{7}$ The concept of weak domination is used here. Börgers (1988) has shown that a slightly stronger concept of domination can be used. He also shows that the result does not depend on the order of elimination of dominated strategies. 
and $\pi_{i}\left(\bar{p}-\rho, p_{-i}\right)>\pi_{i}\left(\bar{p}, p_{-i}\right)$, because $\left(1-1 / n^{*}\right)(\bar{p}-\gamma)\left(\alpha_{1}-\beta_{1} \bar{p}\right)$ $>\rho\left(\alpha_{1}-2 \alpha_{2} \bar{p}+\alpha_{2} \rho+\alpha_{2} \gamma\right)$ for all values of $\bar{p}>\gamma+\rho$ and $\rho$ close to zero.

This means that for all firms $\bar{p}-\rho$ dominates $\bar{p}$. Applying the same argument a large number of times leads to the result that the only strategy that is consistent with common knowledge of profit maximizing behavior is to set $p_{i}$ such that $\gamma<p_{i} \leq \gamma+\rho$, that is, a price very close to the market clearing price.

\section{Cases in Which the Argument Does Not Work}

After this demonstration of the argument it is time to see whether it can be applied to the new classical model. In order to do so we have to look at whether firms are able to determine an upper bound for the prices rational firms may consider. In the previous section $I$ argued that, because the demand equation of the new classical model simply is the Quantity Theory of Money, there is no natural constraint on prices. Moreover, the monopoly price is indeterminate because the $\log$ of a monopolist's revenue equals $M$ $+V$, whatever price is set. So, the monopoly price cannot serve as an upper bound either. As in the previous section the government may be able to solve this dilemma by announcing a credible price restriction.

However, in the context of the new classical model there may be another difficulty in providing the market clearing condition with individualistic foundation. In the above example it is assumed that there are constant marginal costs. However, models in the general equilibrium tradition (hence, new classical models) frequently assume that there are decreasing returns to scale (for example, a quadratic cost function). In these cases the iterative process does not converge to the market clearing price. This is illustrated in the following numerical example. Let the demand function be given by $D(p)=8-p$; let $\rho$ be equal to $1 / 2$ and let there be 2 firms each having a cost function of the form $c\left(q_{i}\right)=q_{i}^{2}$. It is easily verified that the market clearing price equals 4 and the monopoly price equals 6 . If we restrict our attention to prices between 3 and 6 , the normal form of the game is as in Table 1.

From the normal form it is immediately clear that $p_{i}=6$ is dominated by $p_{i}=5 \frac{1}{2}$. As this is common knowledge, the two firms know that their respective competitors will not set a price equal to 6 . In a second round the firms will notice that $p_{i}$ $=5 \frac{1}{2}$ is dominated by $p_{i}=5$. However, none of the other prices 


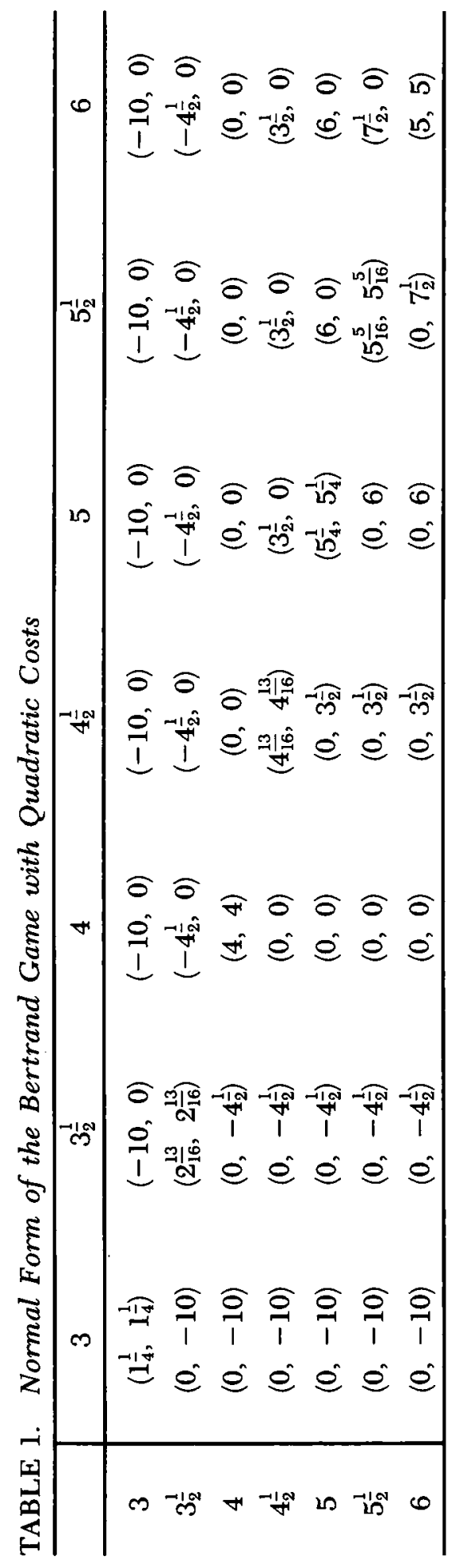


listed in the table can be eliminated in this way because there is a Nash equilibrium for any one of them. The reasons for this being the case do not depend on the specific numerical example that is chosen. The fundamental difference with the constant marginal costs case is that, in the case of decreasing returns to scale, the average cost of production increases with the production level. The firm that sets the lowest price has to serve all the demand. Under decreasing returns to scale a firm's average cost is larger than the average cost it would have had if the two firms had set the same price.

The above discussion shows that the market clearing condition can be provided with individualistic foundations, but only in some rather particular cases. If firms are price setters in a homogeneous market, the demand function has to be such that there is a finite monopoly price and the costs functions have to exhibit constant marginal costs. I think that these conditions are so restrictive that they support the conclusion that the market clearing condition cannot genuinely be regarded as a consequence of common knowledge of rational individual behavior.

\section{Another Argument for Microfoundations}

In the previous sections we have seen that the REH and the market clearing condition are not strongly supported by a theory of individual behavior. However, this should not be interpreted to mean that REH and market clearing are inconsistent with rational behavior. I have only argued that in specific models REH or market clearing cannot be considered as a logical consequence of (common knowledge) of rational behavior. In a large number of models other expectations and other prices than the market clearing prices are consistent with common knowledge of rationality as well. Accordingly, embracing rational individual behavior does not imply that one has to stick to REH and market clearing. This leads me to the conclusion that "microfoundations" and "foundations in the theory of individual behavior" are not equivalent terms and that the reductionist credo alluded to in the introduction does not provide a rationale for this kind of microfoundations.

If this conclusion is granted, one is left with the question, what is accomplished by the microfoundations literature? I think an answer can be formulated along the following lines. Market clearing and perfect foresight (being the deterministic version of the REH) 
have a longstanding tradition in economic theory. Even though the individualistic foundations of these notions are challenged, one can be of the opinion that they are useful tools in economic inquiry. From this point of view a lack of individualistic foundations is not really a problem. Market clearing and REH can be regarded as part of a research methodology in which these notions are generally accepted. This is in line with Weintraub's view that general equilibrium theory is a Lakatosian research program that can be applied to all kinds of economic problems (see Weintraub 1985). In this view the literature on microfoundations simply extends the domain of applications of the general equilibrium methodology to the field of macroeconomics. ${ }^{8}$

After this brief outline of an alternative view of the micro: foundations literature, I turn to the question of whether this kind of microfoundations is necessary in some respect. I think it is, but only in a very narrow sense. The microfoundations literature extends the domain of the general equilibrium methodology similarly to the way Gary Becker's human capital theory has extended the domain of applications of this methodology. From the general equilibrium point of view it is hard to accept that macroeconomics, which constitutes a large part of the domain of economic applications, falls outside its scope. This is the sense in which I would say that microfoundations is necessary: it is a natural domain extension of the general equilibrium methodology. The term "microfoundations" is, however, very misleading. It suggests that it builds macroeconomics only upon the fundamental notion of rational individual behavior. I have extensively argued that this is not what this literature accomplishes. In the microfoundations literature, macroeconomic questions are treated by means of general equilibrium methods. Once the general equilibrium methodology is accepted, this kind of microfoundations is indeed necessary. However those macroeconomists who reject the general equilibrium methodology can still stick to other economic theories that are compatible with the fundamental notion that individuals behave rationally.

Received: February 1990

Revised version: October 1990

\footnotetext{
${ }^{8} \mathrm{~A}$ more detailed description of this view is given in Janssen (1991).
} 


\section{References}

Arrow, Kenneth J. "Towards a Theory of Price Adjustment." In The Allocation of Economic Resources, edited by Moses Abramovitz, 41-51. Stanford: Stanford University Press, 1959.

Bernheim, Douglas. "Rationalizable Strategies." Econometrica 52 (July 1984): 1007-28.

Börgers, Tilman. "Iterated Elimination of Dominated Strategies in a Bertrand-Edgeworth Model." Basel, Switzerland: Universität Basel, 1988.

Evans, George. "The Stability of Rational Expectations in Macroeconomic Models." In Individual Forecast and Aggregate Outcomes: Rational Expectations Examined, edited by Roman Frydman and Edmund Phelps, 69-94. Cambridge: Cambridge University Press, 1983.

Frydman, Roman. "Towards an Understanding of Market Processes: Individual Expectations, Learning and Convergence to Rational Expectations Equilibrium." American Economic Review 72 (September 1982): 652-68.

Frydman, Roman, Gerald O'Driscoll, and Andrew Schotter. "Rational Expectations of Government Policy: An Application of Newcomb's Problem." Southern Economic Journal 49 (October 1982): 311-19.

Frydman, Roman, and Edmund Phelps, eds. Individual Forecast and Aggregate Outcomes: Rational Expectations Examined. Cambridge: Cambridge University Press, 1983.

Gul, Faruk. "Rational Strategic Behaviour and the Notion of Equilibrium." Stanford University, September 1989. Mimeo.

Guesnerie, Roger. "An Exploration of the Eductive Justifications of the Rational Expectations Hypothesis." Paris, DELTA, 1989. Mimeo.

Hahn, Frank H. "Comment." In Individual Forecast and Aggregate Outcomes: Rational Expectations Examined, edited by Roman Frydman and Edmund Phelps. Cambridge: Cambridge University Press, 1983.

Haltiwanger, John, and Michael Waldman. "Limited Rationality and Strategic Complements: the Implications for Macroeconomics." Quarterly Journal of Economics 104 (August 1989): 463-83.

Janssen, Maarten C. W. "Individualistic Foundations for General Equilibrium Theory: A Consideration of Some Game Theoretic Approaches." Recherches Economiques de Louvain 55 (December 1989): 425-46. 


\section{Political Economy 23 (Winter 1991).}

Keynes, John Maynard. The General Theory of Employment, Interest and Money. London: MacMillan, 1936.

Kydland, Finn, and Edward Prescott. "Time to Build and Aggregate Fluctuations." Econometrica 40 (November 1982): 1345-70.

Long, John, and Charles Plosser. "Real Business Cycles." Journal of Political Economy 91 (January 1983): 39-69.

Lucas, Robert. "Some International Evidence on Output Inflation Tradeoffs." American Economic Review 63 (June 1973): 326-34.

Machlup, Fritz. "Micro and Macroeconomics." In Economics Semantics, edited by M. H. Miller, 97-144. Englewood Cliffs, NJ: Prentice-Hall, 1963.

O'Flaherty, Brendan. Rational Commitment: A Foundation for Macroeconomics. Durham: Duke University Press, 1985.

Pearce, David. "Rationalizable Strategic Behavior and the Problem of Perfection." Econometrica 52 (July 1984): 1029-50.

Shubik, Martin. "The General Equilibrium Model is Incomplete and Inadequate for the Reconciliation of Micro and Macroeconomic Theory." Kyklos 28 (August 1975): 545-73.

Tan, Tommy, and Sergio Werlang. "The Bayesian Foundations of Equilibrium Concepts." Journal of Economic Theory 45 (April 1988): 370-91.

Varian, Hal. "Microeconomics." The New Palgrave: A Dictionary of Economics. Vol. 1. London: MacMillan, 1987.

Weintraub, E. Roy. Microfoundations. Cambridge: Cambridge University Press, 1979.

- General Equilibrium Analysis: Study in Appraisal. Cambridge: Cambridge University Press, 1985. 